\title{
Estilo de vida, activismo y consumo en influencers medioambientales en Instagram
}

Lifestyle, activism and consumption in environmental influencers on Instagram

Estilo de vida, ativismo e consumo em influenciadores ambientais no Instagram
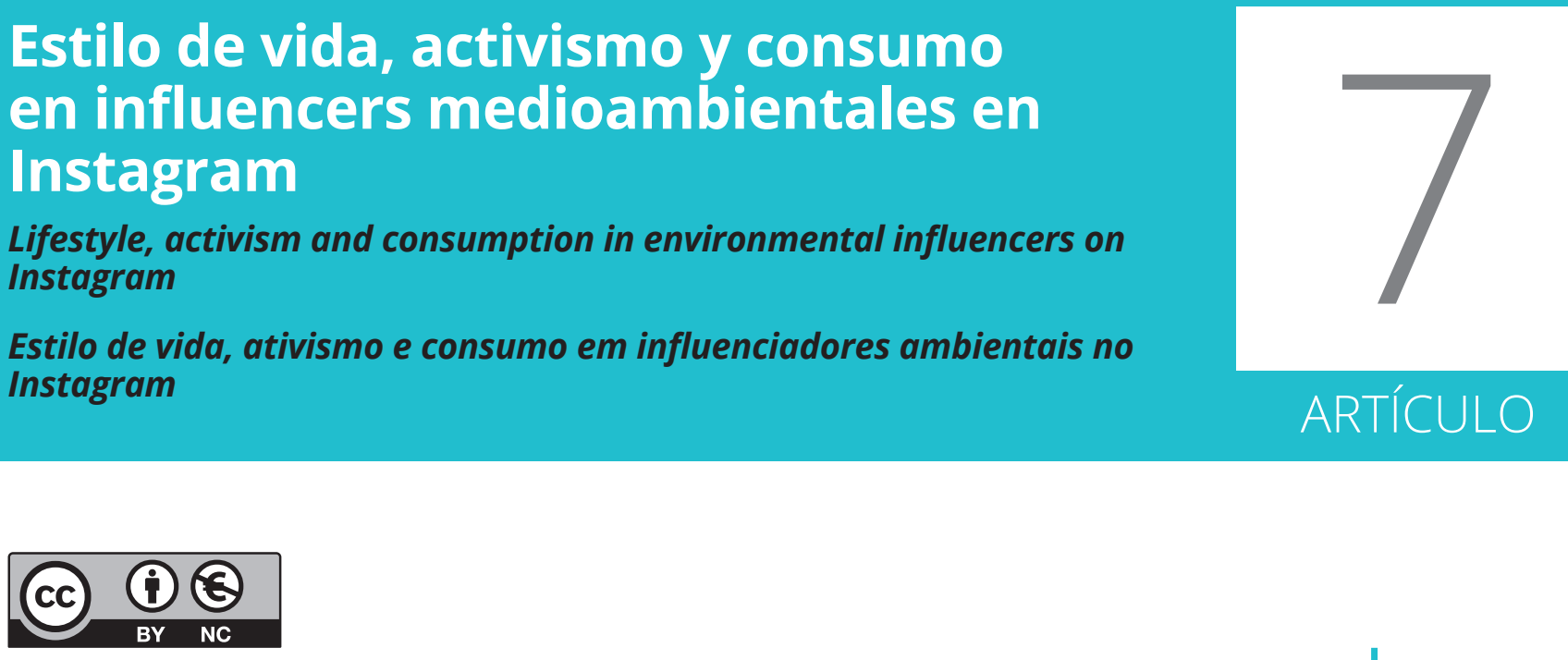

\section{Gemma San Cornelio}

Universitat Oberta de Catalunya (España)

Profesora agregada de los estudios de Ciencias de la Información y la Comunicación de la Universitat Oberta de Catalunya. Docente en el ámbito de comunicación y diseño y directora académica del máster universitario en Diseño, Identidad Visual y Construcción de Marca. Es coordinadora del grupo de investigación Mediaccions, en comunicación y cultura digital, y ha publicado extensamente sobre prácticas creativas y participación en medios digitales, narrativas personales e identidad en internet.

gsan_cornelio@uoc.edu

orcid.org/0000-0002-0788-1483

\section{Elisenda Ardèvol}

Universitat Oberta de Catalunya (España)

Profesora Catedrática en los estudios de Artes y Humanidades de la Universitat Oberta de Catalunya en el ámbito de Antropología Social y Cultural. Ha sido profesora emérita del departamento de Antropología, Historia y Humanidades de Flacso, en Ecuador (2020-2018) y visiting scholar en el Center for Digital Ethnography en el RMIT de Melbourne, en Australia (2015). Ha sido miembro del grupo de investigación interdisciplinar en cultura y comunicación digital Mediaccions (2009-2019) y cuenta con abundantes publicaciones científicas y experiencia investigadora en proyectos nacionales e internacionales en antropología visual, digital y de los medios, con especial énfasis en etnografía y metodologías cualitativas.

eardevol@uoc.edu

orcid.org/0000-0002-5536-9134 


\section{Sandra Martorell}

Universidad Politécnica de Valencia (España)

Investigadora y profesora contratada, doctora del Departamento de Comunicación Audiovisual, Documentación e Historia del Arte de la Universidad Politécnica de Valencia, y miembro del grupo de investigación GAME (Grupo de investigación en Aprendizajes, Medios y Entretenimiento) de la Universitat Oberta de Catalunya. Sus líneas de investigación abarcan principalmente la comunicación y la cultura visual, y ha publicado en diferentes libros y revistas indexadas sobre las redes sociales y la imagen.

sandramartorell@upv.es

orcid.org/0000-0002-4483-1629

RECIBIDO: 05 de mayo de 2021 / ACEPTADO: 13 de septiembre de 2021

\section{Resumen}

La preocupación por la crisis climática ha generado un activismo medioambiental en las redes sociales liderado en buena parte por influencers. En este artículo se aborda la relación entre dicho activismo, el estilo de vida y las narrativas personales en Instagram a partir de un análisis de caso, la cuenta @vivirsinplastico. Se presenta parte de una investigación en curso de carácter cualitativo, cuyos resultados obtenidos nos permiten sostener, entre otros, que la figura del eco-influencer abre un nuevo modo de activismo social basado en promover determinado estilo de vida sostenible en el que las imágenes tienen un papel fundamental.

\section{PALABRAS CLAVE:}

Activismo, Estilo de vida, Influencer, Instagram, Medioambiente, Sostenibilidad.

\section{Abstract}

Concern about the climate crisis has generated environmental activism on social media, largely led by influencers. This article addresses the relationship between such activism, lifestyle and personal narratives on Instagram, based on a case analysis of the account @vivirsinplastico. Part of an ongoing qualitative research is presented, the results of which allow us to argue that the figure of the "eco-influencer" opens up a new mode of social activism based on promoting a certain sustainable lifestyle in which images play a fundamental role.

\section{KEYWORDS}

Activism, Lifestyle, Influencer, Instagram, Environment, Sustainability.

\section{Resumo}

A preocupação com a crise climática gerou ativismo ambiental nas redes sociais, em grande parte liderado por influenciadores. Este artigo aborda a relação entre tal ativismo, estilo de vida e narrativas pessoais no Instagram a partir de uma análise de caso, da conta@ @vivirsinplastico. Apresenta-se parte de uma pesquisa qualitativa em andamento, cujos resultados nos permitem sustentar, entre outros, que a figura do "eco-influencer" abre um novo modo de ativismo social baseado na promoção de um certo estilo de vida sustentável no qual as imagens têm um papel fundamental.

\section{Palavras-chave}

Ativismo, Estilo de vida, Influenciador, Instagram, Meio ambiente, Sustentabilidade. 


\section{INTRODUCCIÓN}

Instagram se presenta como un espacio de comunicación en el que encontramos perfiles de influencers cuya narrativa personal plantea una relación directa entre un estilo de vida ecológico y un consumo sostenible. Esta tipología de usuarios propone una forma de activismo que presenta unas características específicas.

El papel de los medios de comunicación en el ámbito de la concienciación medioambiental resulta clave desde hace algunas décadas, ya que se considera que los ciudadanos no visualizan las consecuencias del deterioro medioambiental de un modo inmediato (Olausson, 2011; Östman, 2014). De este modo, se argumenta que los medios son de gran valor a la hora de fomentar y consolidar la conciencia y las acciones respecto al medio ambiente. Aunque, de acuerdo con Arlt et al., (2011), estos mensajes no acaban de ser efectivos, especialmente cuando implican un cambio en el estilo de vida que nos haga renunciar a ciertas comodidades. Según estos autores, las acciones mediáticas más eficaces en general se pueden observar en aquellos casos que usan varios medios: es decir, las noticias de la televisión pública, los medios impresos y los medios de información en línea (Arlt et al., 2011), en este sentido, las redes sociales tendrían potencial para activar la participación en movimientos de base medioambiental (Huang, 2016).

El activismo medioambiental promovido por entidades como Greenpeace ha fomentado la participación de la ciudadanía en acciones de protesta y mayoritariamente ha priorizado el uso de imágenes negativas de degradación del medio ambiente. Sin embargo, en un estudio realizado por Leviston et al. (2014) encontraron que las imágenes de los desastres naturales, los fenómenos extremos y la contaminación provocan respuestas negativas en la audiencia, mientras que las respuestas a las imágenes que representan soluciones climáticas generaron reacciones más positivas, lo que supone una alternativa a la forma tradicional de comunicar el ecologismo.

Así, pues, el potencial de los medios de comunicación y los movimientos sociales ante el cambio climático se situaría en la capacidad de promover una conciencia estable de los problemas climáticos y lograr un cambio de actitud al respecto. Es decir, se parte de la idea de que, a largo plazo, los medios y las movilizaciones pueden provocar, indirectamente, cambios en las preferencias de los consumidores, asociados a un cambio en el estilo de vida (Holbert et al., 2003).

En el contexto comunicativo actual las redes sociales tienen un rol esencial, especialmente Instagram, donde abundan los perfiles dedicados a difundir determinados estilos de vida. El objetivo de esta investigación es explorar la relación que se establece entre las narraciones personales, el estilo de vida y el activismo medioambiental en Instagram. Se analizan mediante métodos cualitativos, un conjunto de perfiles -con un volumen de seguidores destacable- dedicados a la divulgación de la ecología y la sostenibilidad con el fin de demostrar la emergencia de nuevas formas de activismo que presentan características propias.

Este activismo propone un cambio ecológico a partir del espacio doméstico, basado en elecciones de consumo responsable (bienes de consumo respetuosos con el medioambiente), o de la reducción del consumo al máximo como solución. Así, pues, la articulación de activismo y consumo será uno de los ejes del análisis. Por otro lado, en Instagram el papel de la imagen resulta imprescindible para fundamentar estas narrativas medioambientales $y$, en este sentido, es interesante analizar la emergencia de un activismo visual y de una estética determinada que acompaña a este movimiento en dicha red social. 


\section{MARCO TEÓRICO Y ESTADO DE LA CUESTIÓN}

\subsection{CELEBRITIES Y ACTIVISMO MEDIOAMBIENTAL EN LAS REDES SOCIALES}

La presencia de personajes famosos dedicados a la causa medioambiental ya tiene un cierto recorrido, si consideramos por ejemplo a Al Gore o Leonardo di Caprio. Según Abidin et al. (2020), si bien la función de estas celebridades es fundamental a la hora poner algunos temas sobre la mesa, en otros casos pueden contribuir a procesos de comodificación de los paisajes o entornos naturales contribuyendo al capitalismo consumista (Abidin et al., 2020, p. 16). Se han realizado asimismo varios estudios recientes sobre la influencia de Greta Thunberg en los jóvenes (Pihkala, 2018) que destacan su poder de convocatoria.

Sin embargo, menos atención han recibido el papel que tienen unos nuevos actores dentro del ecosistema de las redes sociales: Ios influencers medioambientales, que denominamos de manera tentativa eco-influencers (Ardèvol et al., 2021). Mediante la promoción de un estilo de vida y utilizando su propia experiencia y narrativa personal, estos nuevos actores mediáticos educan y se comprometen con su comunidad de seguidores, hecho que les legitima y les motiva a no abandonar este cometido.

El término influencers se desarrolla fundamentalmente en los estudios de marketing, como es el caso de Pino-Romero y Castelló-Martínez (2017), que analizan los vínculos existentes entre las marcas y los influencers, y los influencers especializados en moda en España (Cuenca-Piqueras, 2021; Segarra-Saavedra \& Hidalgo-Marí, 2018).

No obstante, la aproximación de este estudio se sitúa dentro de la cultura digital, de forma análoga al estudio de las micro celebrities y el self-branding desarrollado por Senft (2013) o Marwick (2013) y vinculado a usuarios anónimos que se convirtieron en prescriptores publicando contenido en blogs o en Youtube, por ejemplo. En este sentido, la figura del influencer se caracteriza por: 1) aplicar estrategias positivas de self-branding, 2) gestionar su visibilidad en los medios digitales 3) cultivar su comunidad de seguidores para que el consumo de su contenido les sirva de inspiración, adoptando técnicas de relato coherentes con sus estilos de vida (Leaver et al., 2020, p. 106). Según Ardèvol y Márquez (2017, p. 75) el éxito de estas figuras mediáticas se basa en su estilo comunicativo directo, íntimo y sincero con su audiencia.

En esta investigación se utiliza el término eco-influencers en Instagram en referencia a los perfiles comprometidos con la difusión de contenidos de temática medioambiental. Estos usuarios, que no están necesariamente involucrados en estructuras de organización social y activismo tradicional, promueven un estilo de vida sostenible mediante su propio ejemplo, que se convierte en el objetivo y tema principal de sus comunicaciones.

Se podría decir que la figura del eco-influencer responde a un activismo medioambiental que promueve un cambio sustentable a través de la incorporación del mismo a sus propias vidas. En este sentido presenta similitudes con otros influencers, por ejemplo aquellos que promueven la alimentación saludable (Marauri et al.,2021).

Sin embargo, se diferencian del activismo clásico en varios aspectos: el más destacable es que sus propuestas se enmarcan, de un modo general, en la acción individual, no tanto en la acción colectiva, ya que no presentan una articulación colectiva a priori (aunque puedan adherirse a campañas como el \#futuristicfe- 
bruary ${ }^{1}$ o \#Fridaysforfuture ${ }^{2}$ ). Otro aspecto destacable es su estrecha relación con el consumo y con marcas que promueven una relación sostenible con el entorno. Estos, junto con los perfiles eco-influencers, formarían parte de un mercado emergente de defensa de lo ecológico y lo sostenible en vías de consolidación.

\subsection{CONSUMO, ESTILO DE VIDA Y ACTIVISMO}

De acuerdo con Featherstone (1987, p. 59), "Ios nuevos héroes de la cultura del consumo hacen del estilo de vida un proyecto de vida personal y expresan su individualidad a través de su estilo, en el sentido del particular ensamblaje que hacen de bienes, ropa, prácticas, experiencias, apariencia corporal y disposiciones". Así, pues, si entendemos las prácticas de vestuario, higiene, ahorro, dieta, limpieza de playas... que promueven los eco-influencers en su búsqueda de un estilo de vida sostenible, este modelo podría tener un impacto global en la generación de nuevas pautas de consumo o, en algunos casos, de no consumo a partir de la acción de muchas personas. Este activismo buscaría el cambio en los hábitos de consumo a partir de una acción directa y cotidiana, basada en pequeñas acciones en el día a día y en el espacio doméstico. De este modo, la preocupación por un estilo de vida propio y auténtico que promueve la cultura del consumo se hibrida, al menos en este caso de estudio, con la propuesta de un cambio social en las aspiraciones colectivas.

1 Es un desafío o challenge impulsado por la cuenta de Instagram @sustainable_duo. Consiste en guardar durante el mes de febrero todos residuos plásticos y no biodegradables que generamos y publicar una foto con ellos. Acumularlos y convivir con ellos nos hace tomar conciencia de la cantidad de basura que generamos y el impacto que tiene en el planeta.

2 Movimiento protagonizado por jóvenes que cada viernes protestaban unidos contra el calentamiento global.
El activismo medioambiental del eco-influencer se situaría, pues, a un nivel individual, en el sentido de que genera una confianza en que nuestras acciones individuales, si son muchas y coordinadas, pueden provocar un cambio real, efectivo y duradero también en las estructuras productivas.

Se podría argumentar, pues, que las redes sociales y la figura del influencer abren nuevos modos de activismo social basado en promover un determinado estilo de vida. Los eco-influencers buscan crear un público que comparta sus aspiraciones y, de ese modo, la construcción de un estilo de vida se vincula no solo a una nueva moda o gusto personal sino a una propuesta de acción colectiva para promover un estilo de vida basado en unos valores compartidos y en unas prácticas comunes. Este punto lo diferenciaría de otras 'modas' o estilos juveniles a los que el mercado se ha adaptado sin que se produzca un cambio en las estructuras productivas ni en las formas de organización social o política.

Por este motivo Haenfler et al. (2012) afirman que la separación entre estilos de vida y movimientos sociales ha dejado un punto ciego, situado en la intersección entre la acción individual privada y el activismo, el cambio personal y el social, la identidad personal y la colectiva. Ellos proponen el concepto de movimientos sociales alrededor del estilo de vida (lifestyle movements) como capaces de promover activamente nuevos valores y significados culturales, desafiando la cultura hegemónica y fomentando un cambio social más amplio. Este nuevo activismo se basa en tres características: a) las elecciones en el modo de vida como táctica para el cambio social; b) la centralidad de la identidad personal como motor del cambio y c) una estructura organizativa difusa (Haenfler et al., 2012, p. 2). 
En contraposición a las movilizaciones del consumo, por ejemplo, a través de boicots a determinadas marcas, el cambio en el estilo de vida se plantea como algo permanente, que tiene un efecto más a largo plazo (Holzer, 2006). Dicho de otra manera, podríamos argumentar, de acuerdo con Schlosberg y Coles (2016), que el estilo de vida sostenible y ecológico, el consumo verde y las prácticas anti consumo (Black \& Cherrier, 2010, p. 439) difundidos a través de las redes sociales pueden considerarse como un tipo de movimiento social al promover flujos de acciones alternativas.

\subsection{ESTÉTICA Y ACTIVISMO VISUAL EN INSTAGRAM}

Varios autores han teorizado la estrecha relación entre consumo, diseño y estética en la sociedad contemporánea. Lipovetsky y Serroy (2015) destacan la importancia del diseño y la fotografía, potenciados, en parte, por las redes sociales, como vehículo de transmisión de estilos visuales y de adquisición de competencias estéticas. Esta cuestión es claramente visible en el caso de Instagram, considerada por la mayoría de los usuarios como la red donde el aspecto del contenido es lo más importante. No obstante, Instagram va más allá de esta cuestión. En el congreso Studying Instagram Beyond Selfies ${ }^{3}$ (2018) se discutió en torno a la evolución de la investigación sobre Instagram, apuntando precisamente hacia su politización o a su uso en el ámbito del activismo. La pregunta que se plantea entonces es: ¿Una red basada en la estética puede ser vehiculadora del cambio social?

El uso político de las redes sociales ha sido largamente estudiado en los últimos años (Postill,

3 https://londonenglish.live/2018/03/23/studying-instagram-beyond-selfies-instagram-conference-2018-01-june-2018-middlesex-university/
2018; Treré, 2018) especialmente centrados en Twitter. Sin embargo, el papel de las imágenes en los movimientos sociales no ha sido tan profusamente estudiado, quizás porque generalmente estas suelen estar circunscritas al contexto local (Doerr \& Teune, 2012). En todo caso, el concepto más específico de activismo visual suele estar referido a colectivos artísticos o creativos, que ponen sus competencias visuales y performativas al servicio de una causa. Para Demos (2016) el concepto ofrece una propuesta provocativa, pero a la vez admite que el activismo visual podría estar debilitando metodológicamente su propósito político, por estar dirigido al disfrute estético, espectacularizado, vendido y consumido por aquellos políticamente opuestos. De este modo, se entiende que el activismo visual, en tanto que estético, perdería fuerza.

Sin embargo, en Instagram los activistas medioambientales proponen unas narrativas personales, el papel de cuyas imágenes es fundamental. Por tanto, cabe explorar la relación entre la estética de Instagram (Leaver et al., 2020) y el activismo visual.

\section{OBJETIVOS Y METODOLOGÍA}

Como se ha avanzado, el objetivo de esta investigación es explorar la relación que se establece entre las narraciones personales, el estilo de vida y el activismo medioambiental en Instagram.

Este objetivo se estructura en los puntos que se enumeran a continuación. En primer lugar, se pretende constatar la existencia de la categoría emergente de influencers medioambientales. En segundo lugar, se persigue comprender y caracterizar la propuesta de activismo que plantean en lo referente a su relación con 
los conceptos de estilo de vida y consumo. Finalmente, se persigue profundizar en el papel que desempeñan las imágenes y su relación con el activismo visual.

Para ello, la aproximación metodológica utilizada es un remix (Markham, 2013) de métodos de orientación cualitativa que combina la observación participante en línea con la entrevista en profundidad y el análisis narrativo. Partimos de la dualidad de Internet como método y campo de estudio (Hine, 2005). Internet no es solo una herramienta de investigación para recopilar datos, también es el campo empírico donde se realiza la investigación; las redes sociales son formas de publicación, pero también constituyen el contexto social donde las personas se encuentran e interactúan (Ardèvol \& Gómez-Cruz, 2012). De este modo, el trabajo de campo ha consistido en la creación de un perfil de investigación en Instagram y el seguimiento continuado — de junio de 2020 a junio de 2021 - de distintos perfiles para constituir nuestro campo de estudio, que nos ha permitido realizar 13 entrevistas en profundidad por vía telemática. ${ }^{4}$

La muestra delimitada se compone de 60 cuentas de Instagram, cuyo objetivo es la divulgación de contenidos medioambientales. Es una muestra teórica (Strauss \& Corbin, 1994) ya que busca maximizar las diferencias y variedad de contenidos y enfoques, y se ha generado mediante el sistema 'bola de nieve' en el que unos usuarios llevan a los siguientes porque se siguen mutuamente o comparten los mismos hashtags en sus publicaciones, pero también automatizado por las recomendaciones del

4 Listadas al final del artículo en la bibliografía. En este artículo nos centramos en la primera de ellas, aunque en los subsiguientes artículos abordamos otros aspectos que emergen de nuestro trabajo de campo (véase Ardèvol et al., 2021). propio sistema algorítmico de Instagram, que detecta usuarios afines. En ese sentido se considera que esta muestra ha alcanzado la saturación dado que, aunque se ha ampliado el número de perfiles seguidos con el fin de encontrar nuevas particularidades, no se ha detectado ningún cambio sustantivo que obligue a variar la caracterización de la muestra inicial ya que el propósito no es obtener datos representativos estadísticamente, sino una tipología significativa en términos de caracterización del universo estudiado.

\subsection{DESCRIPCIÓN Y CARACTERIZACIÓN DE LOS PERFILES ESTUDIADOS}

Para la elaboración de la muestra se han tenido en cuenta los siguientes criterios: a) máxima variabilidad de perfiles y estilos narrativos que tengan como tema la sostenibilidad, el medioambiente y el cambio climático; b) idioma: dado que el universo de la muestra es global y local, se incluyen perfiles tanto en inglés (30) como en castellano (25) y otros idiomas como el catalán y el alemán (5); c) volumen de seguidores.

En relación con este último criterio es importante destacar que, de acuerdo con la clasificación de las tipologías de influencers por volumen de seguidores, ${ }^{5}$ el grueso de las cuentas estudiadas en esta investigación se sitúa entre el rango de micro influencers (10.000100.000 seguidores) y el de los mid-tier influencers (100.000-500.000 seguidores), que están bastante equiparados (21 y 22 cuentas respectivamente). Algunos ejemplos de cuentas en el

5 Atendiendo a la clasificación propuesta por Launchmetrics (www.launchmetrics.com) la categoría micro influencer se sitúa entre los 10.000 y los 100.000 seguidores; la categoría mid-tier, entre los 100.000 y los 500.000; la categoria mega entre los 500.000 y los 2.000.000, y la categoría all-star supera los 2.000.000. 
rango de mid-tier serían las cuentas @carlotabruna o @the.eco.warrior. En el rango de macro influencer (500.000-2.000.000 seguidores) hay 7 cuentas, como @nancy_risol o @thezerowasteguide y en el de all-star 5, incluyendo, por ejemplo, a @kristenanniebelly @kortajarenajon, que combinan en su feed activismo y otros tipos de contenido. Además, se ha añadido una quinta categoría, denominada nano influencers, que incluye 5 cuentas en otros idiomas que tienen menos de 10.000 seguidores.

Una cuestión destacable en el conjunto de perfiles seleccionados es que hay una presencia femenina muy importante. De un total de 60 cuentas, 22 están visiblemente gestionadas por mujeres, y únicamente 7 se identifican con

\section{Figura 1}

Distribución de cuentas por número de seguidores 60

40

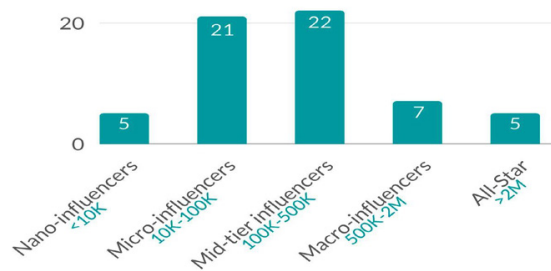

usuarios masculinos. El resto de los casos corresponden a cuentas con una titularidad o liderazgo diverso, incluyendo perfiles anónimos, colectivos o corporativos (Figura 2).

Este sesgo se debe, en parte, al método utilizado para construir la muestra (además de sugerir temáticas similares, es posible que el algoritmo de recomendación también sugiera usuarios con características similares). No obstante, esta preeminencia de usuarias coincide con otros estudios (Filgueiras, 2019; Murphy, 2019; Shabir, 2020) dedicados a la emergencia del activismo medioambiental en Instagram.
Figura 2

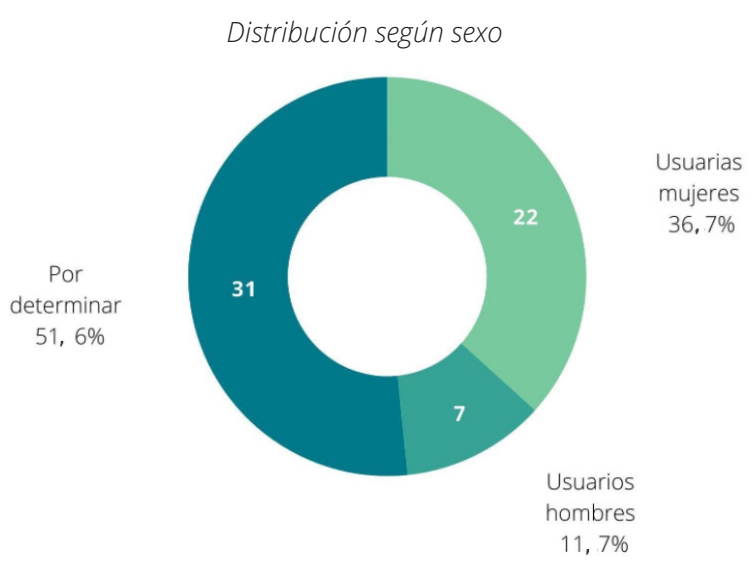

Además, en el estudio de Shabir, el $94 \%$ de las seguidoras de estas cuentas también son mujeres (Shabir, 2020, p. 25). Este porcentaje coincide también, como cuentan en la entrevista en profundidad, con el $90 \%$ de seguidoras de la comunidad de @vivirsinplastico, o el 75 \% de las seguidoras de @publiclandhatesyou (otro de los casos estudiados).

La observación participante y las entrevistas en profundidad indican, por una parte, una cierta vinculación de este tipo de activismo con el eco feminismo, y por otra, un empoderamiento de las mujeres en este tipo de lucha medioambiental a partir de la vida cotidiana, el consumo y el espacio doméstico. Es importante destacar, además, la presencia de cuentas que son impulsadas por parejas y familias (de dos o más personas), 6 en total, por ejemplo @nubiaehijos, @petitapetjada o @sustainableduo. Son parejas o familias que han decidido emprender un proceso de cambio en su vida doméstica para eliminar el plástico en el hogar, realizar un consumo de productos sostenibles y de proximidad, etc. y que han decidido compartir su experiencia abriendo una cuenta en Instagram, pero también en otras redes sociales, e incluso, mucho antes o en paralelo, abriendo un blog donde poder ampliar sus narrativas. Este dato es relevante y quizás es indicativo de una tendencia dentro de esta forma de activismo. 
El resto de las cuentas no presentan una identidad personal o familiar, sino que pertenecen a colectivos de amigos $u$ organizaciones como @greenpeace y cuentas dedicadas, en mayor o menor medida, a la venta de productos ecológicos, como @esturirafi, llevada por dos hermanas que montaron su empresa a partir de seleccionar y probar ellas mismas los productos a la venta. Aunque las personas que inician sus cuentas como motivación personal se consideran ante todo activistas y no influencers propiamente, ya que no suelen publicitar marcas en sus perfiles, las cuentas administradas por pequeños comercios online y offline suelen reclamar que, si bien pretenden ganarse la vida a través de la venta de sus productos, están cercanos al activismo, prueban y seleccionan las marcas en función de sus criterios medioambientales y estéticos, y promueven también un estilo de vida acorde con las personas activistas, a las que siguen y con las cuales interactúan.

A diferencia de las tres categorías que encuentra Shabir (2020) en su muestra: 1) comercios o tiendas, 2) influencers y blogueras de estilo de vida y 3) trucos y consejos para una vida más sostenible, nuestra apreciación es que estas categorías se hibridan entre los distintos perfiles de la muestra que utilizamos y resulta difícil establecer los límites entre ellas. No obstante, adaptando esta clasificación a nuestra muestra encontramos: 1) activistas y blogueras de estilo de vida que, a su vez, pueden ser cuentas personales, en pareja o familiares dedicadas exclusivamente al medio ambiente y al consumo sostenible; 2 ) influencers y blogueras de estilo de vida que además promocionan productos eco; 3) trucos, consejos y memes; generalmente administrados de forma individual o colectiva y que suelen ser anónimos; 4) tiendas o pequeños productores; 5) colectivos y organizaciones, más enfocados a la concienciación y movilización colectiva sobre el medioambiente. En este estudio se consideran eco-influencers las tres primeras categorías, aunque en su conjunto formarían parte de una "eco esfera" en la que se hibridan activismo medioambiental, mercado y consumo ecológico, y propuestas de un estilo de vida sostenible y saludable.

\section{ESTUDIO DE CASO @ VIVIRSINPLASTICO}

\subsection{DESCRIPCIÓN DEL CASO}

A partir de esta primera aproximación se decide profundizar en un número de cuentas más reducido. En este artículo se analiza la cuenta @vivirsinplastico, impulsada por una pareja que se presenta como Patri y Fer, y que explica su experiencia desde que decidieron eliminar el consumo de plástico (hace 5 años), compartiendo consejos sobre ello con su comunidad de seguidores (67.600 en el momento de escribir este artículo).

Para el estudio de caso se analizaron los contenidos (narrativas e imágenes) publicados en esta cuenta en su conjunto (576 posts a día 26/11/20) especialmente los posts publicados en los últimos 2 meses (7 a día 26/11/20). Por otro lado, se realizó una entrevista en profundidad a los impulsores del proyecto donde se les preguntaba por los siguientes aspectos: a) el origen y la motivación del proyecto, b) sus percepciones acerca del concepto de influencer y su relación con el activismo y el consumo, c) su proceso creativo, d) la relación con su audiencia y e) sus expectativas en cuanto al proyecto.

Para el análisis de las narraciones personales en Instagram se utiliza el concepto de 'pequeñas historias' (small stories) (Georgakopoulou, 2016) basado en un análisis de las distintas formas semióticas (incluidas las imágenes y narra- 
tivas colaborativas) de las publicaciones de los perfiles seleccionados.

\subsection{ANÁLISIS Y RESULTADOS}

\subsubsection{NARRATIVA PERSONAL E IMÁGENES}

Como se ha avanzado, Patri y Fer son una pareja (en sus cuarenta) que decidieron realizar un cambio en su estilo de vida reduciendo el consumo de plásticos. De manera simultánea, comenzaron a escribir un blog donde contaban su experiencia. Unos meses más tarde abrieron una cuenta también en Instagram. Actualmente, su ecosistema en las redes sociales incluye además una cuenta de Facebook, Twitter, LinkedIn y Youtube. El espacio con más seguidores es Instagram, lo que ha modificado en cierto modo su proceso creativo: antes pensaban primero en el blog, pero ahora tienden a pensar primero en contenido para Instagram, aunque a menudo lo aprovechan y lo amplían, y así también tiene cabida en el blog.

Resulta interesante destacar cómo el hecho de compartir su proceso de cambio a una vida sin plástico con una audiencia imaginada significó para ellos una forma de obligarse a seguir con su propósito, de asumir un compromiso de un modo público, además de hacer llegar su mensaje a otras personas. En este sentido, su primer post en Instagram es una fotografía de su basura acompañada del texto: "Esta es la basura que generamos la semana 0 de nuestro reto \#Vivirsinplastico para reconocer los plásticos que consumíamos a diario". Durante el primer mes de su cambio de vida, observamos que cada entrada refleja la cantidad de plástico consumido, al mismo tiempo que reciben comentarios que los animan a continuar con el reto que se han propuesto (Figura 3).

A día de hoy, publican posts de diversa índole: basura que recogen en playas, noticias de
Figura 3

Primer post de @vivirsinplástico del 21-08-2015
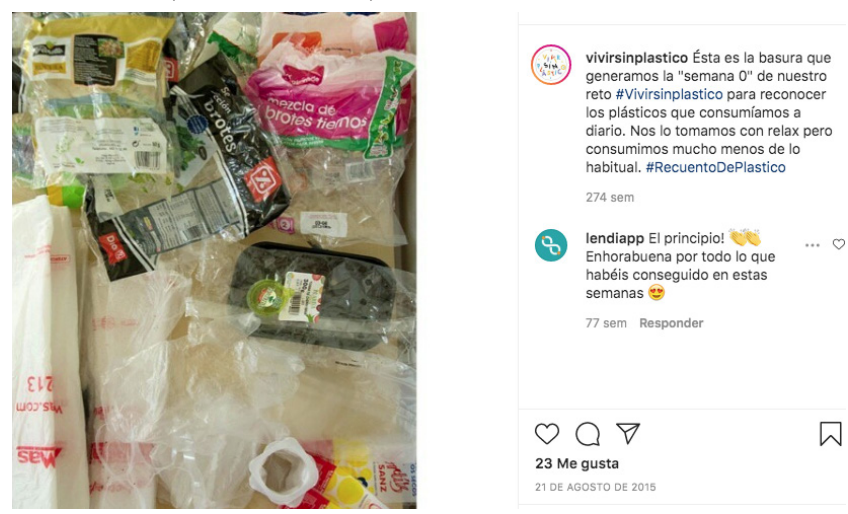

$\underset{23 \text { Me gusta }}{\bigcirc} \nabla$

Fuente: @vivirsinplastico

https://WWW.instagram.com/p/6pz7gTRYM9/

medios de comunicación, encuestas, lecturas, mensajes motivadores, trucos de reciclaje, prácticas de vida sostenible, etc.

El relato sobre un cambio de vida se reproduce de una manera constante en otros perfiles (@ margreen, @laurainwaterland o @sustainableduo): hay un momento revelación (una visita a una playa, un viaje familiar) que les hace conscientes de la necesidad de contribuir a la sostenibilidad y compartir esta voluntad de cambio. Por ello, cada cierto tiempo publican un post donde recuerdan el origen de su cuenta y su motivación.

En cuanto a las imágenes en Instagram, @ vivirsinplastico realiza sus publicaciones con criterio estético, lo que denota sensibilidad y conocimientos en materia de fotografía e imagen (en la entrevista se constata la formación de ambos en este ámbito). Se identifican las siguientes tipologías de las imágenes publicadas: bodegones de fruta y verdura, imágenes de eventos, promoción de su libro, detalles de objetos, fotos denuncia (por ejemplo, frutas envueltas en plástico), infografías, productos alternativos y composiciones a partir de basura recogida. A pesar de que no existe un criterio formal específico en el conjunto del grid, sí que se detecta una intención para mostrar, de un 
Figura 4

Composición de frutas y verduras

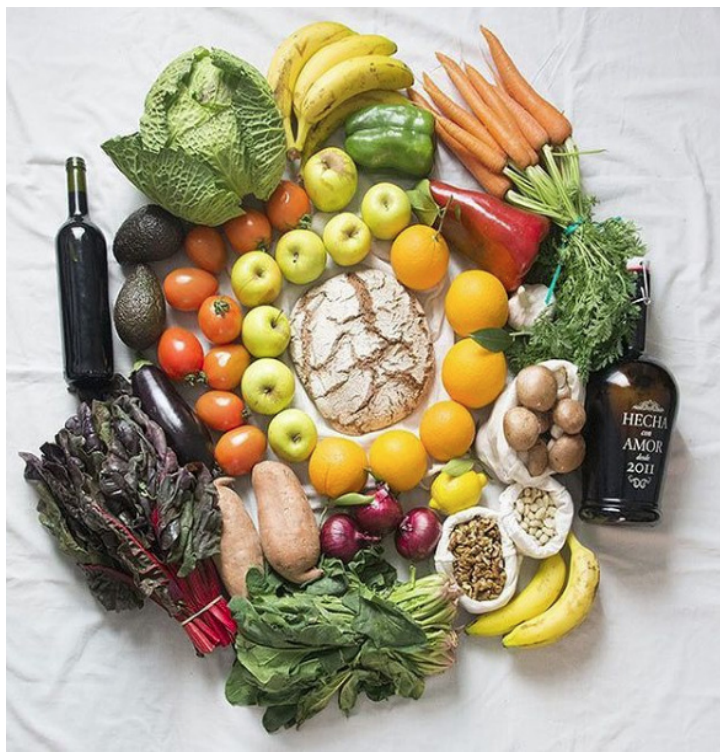

Fuente: @vivirsinplastico

https://www.instagram.com/p/BQw-f8kgOWp/

Figura 5

Composición realizada con residuos encontrados en la playa

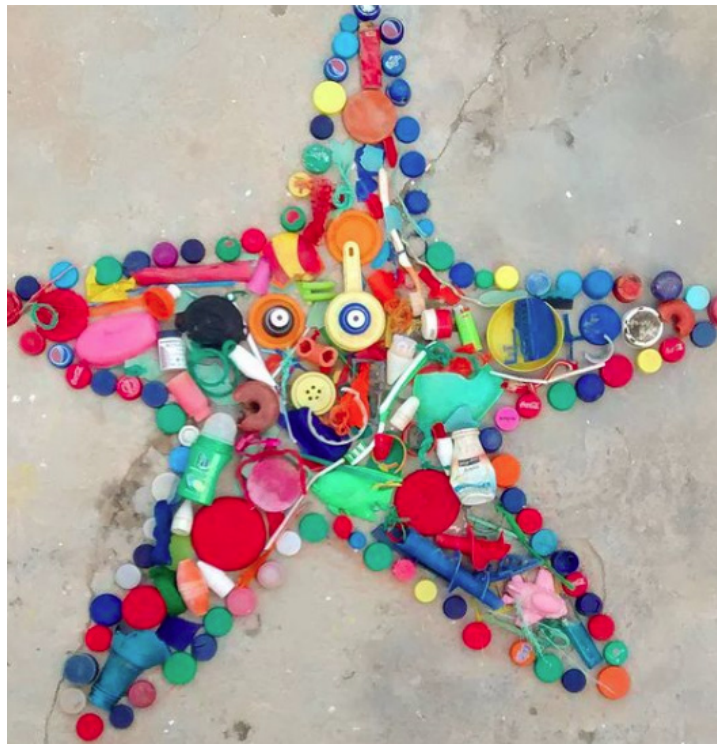

Fuente: @vivirsinplastico

https://www.instagram.com/p/91KFFoRYFu/

modo visualmente atractivo, sus informaciones, por ejemplo, utilizando un punto de vista cenital para remarcar la geometría y la simetría en los alimentos o en las formas realizadas a partir de los residuos recogidos en la playa (Figura 4 y 5 ).
Con el tiempo, su actividad de publicación ha ido tomando más protagonismo en Instagram, ya que muchas veces el público al que se dirigen no llega al blog. De todos los contenidos publicados, ellos destacan la preferencia de su comunidad por las cuestiones personales. Cuando cuentan anécdotas o experiencias propias es cuando reciben más likes, comentarios u otro tipo de interacciones. Por ejemplo, en este post del 2 de agosto de 2020 publican una foto personal y el comentario siguiente:

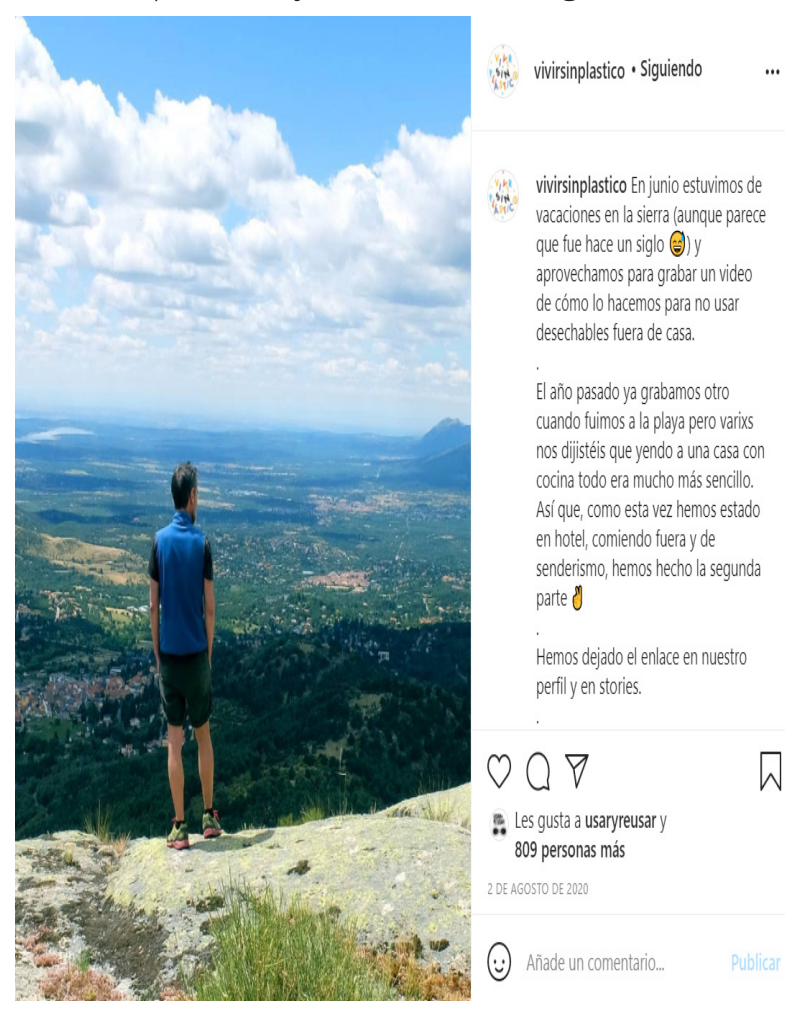

Fuente: @vivirsinplastico

https://www.instagram.com/p/CDZKW8FqPWx/

En este texto se aprecia la interacción con su comunidad, recogen sus opiniones y proponen una respuesta participativa que recibe 813 likes y 34 respuestas. Destacamos una de ellas:

Lo más complicado es encontrar donde comprar a granel dependiendo de donde estés. Y los sitios donde siguen insistiendo en que te tienen q poner una bolsita... Gracias por toda la info super útil q dais y por ser un referente!! 
Esta imbricación de la narrativa personal en su propósito divulgador del problema del plástico permite entender este tipo de prácticas a partir del concepto de pequeñas historias personales (small stories) que se desarrollan de manera discontinua en el feed de @vivirsinplastico, así como en los comentarios recibidos y en las conversaciones desarrolladas mediante mensajes directos, "nos escribe mucha gente por privado" (Vivir sin plástico, 2020). La narrativa personal, vinculada al estilo de vida propuesto por Patri y Fer, tendría todas las características de una small narrative (Georgakopoulou, 2016) apoyada en un conjunto de imágenes que captan la atención y que se desarrollan, de un modo 'amable' en el contexto de Instagram. Siguiendo a esta autora, no son historias que tengan un inicio, desarrollo y final, sino pequeñas historias personales que narran una situación y un contexto e invitan a la interacción a través de continuar con otras historias que la completen.

\subsubsection{RETÓRICAS DEL CAMBIO, ACTIVISMO E INFLUENCIA}

De la observación del perfil @vivirsinplastico se puede inferir que su mensaje pretende contribuir al cambio social desde las pequeñas acciones domésticas, como un cambio de hábitos en el consumo diario. En este cambio social se percibe como necesario educar y comunicar de forma reiterada las ideas, tal y como afirman en la entrevista, distinguiendo entre los nuevos seguidores - que tienen unas necesidades de conocimientos básicos - y los avanzados que llevan tiempo siguiéndoles - (este aspecto aparece también en otros entrevistados como @publiclandhatesyou o @zeroxplastic).

Cabe destacar que, en relación con la idea de activismo y la emergencia de estos perfiles en Instagram, ellos sí se perciben a sí mismos como activistas. No sería un activismo tradicio- nal, sino alternativo, desde lo cotidiano. Este tipo de activismo del día a día, de los pequeños gestos, encajaría perfectamente con el activismo de los movimientos de estilo de vida lifestyle movements (Haenfler et al., 2012).

Así, la actividad de @vivirsinplastico se desarrolla fundamentalmente online, aunque cada vez están teniendo más repercusión y realizan más actividades offline (presentación de libros, conferencias, etc.). En su caso, se da una progresión del blog personal a las redes sociales y de un compromiso personal evolucionan hacia a la posibilidad de poder vivir dedicándose exclusivamente a su tarea de concienciación e información. Además de escribir un libro y promocionarlo en sus redes, el año pasado deciden dar un paso más y constituirse como asociación sin ánimo de lucro, a la vez que abren una cuenta de mecenazgo en Patreon.

Aun así, Patri y Fer se consideran más activistas que influencers o comunicadores, a pesar de que reconocen que han contribuido al cambio de marco mental de mucha gente que les sigue. En este sentido, se desmarcan de las nociones de influencer más convencionales asociadas al mundo del marketing y remarcan su aspiración a crear un movimiento más potente en la concienciación, más allá de los likes. "No queremos ser esclavos del algoritmo" (Vivir sin plástico, 2020). Esta cuestión se presenta fundamental a la hora de conceptualizar este fenómeno emergente, esta figura de influencia en las redes. Otros casos estudiados también presentan una relación ambivalente con la noción de influencer (aunque en el fondo todos reconocen su influencia positiva sobre su comunidad) y ofrecen matices con respecto a su visión sobre el activismo. 


\subsubsection{EL CONSUMO COMO CAMBIO DE VIDA}

La propuesta de @vivirsinplastico se basa en reducir el consumo, comprando únicamente aquello que verdaderamente necesitan. Dentro de este planteamiento, lo que compran proponen que sea lo más sostenible posible, evitando plásticos, fomentando el embalaje y bolsas reutilizables, apostando por los mercados de agricultores directos al consumidor $y$, en general, productos alternativos a otros más contaminantes.

En contraste con otros perfiles de nuestra muestra, que promocionan abiertamente productos de naturaleza ecológica, este no lo hace. Si bien les han realizado propuestas de promocionar productos, suelen mantenerse bastante al margen de este tipo de actividad, en cuanto que una de sus máximas es evitar un consumo innecesario. En cinco años solo han aceptado dos proyectos porque encajaban muy claramente con sus objetivos. Uno de estos productos es Storytel, que ofrece una versión del libro que han publicado, y el otro es el Festival Son Estrella Galicia Posidonia, que dedica parte de los beneficios a la conservación de la posidonia.

Durante la andadura del proyecto demuestran conocer a su audiencia y calculan que la mayoría son mujeres de entre 20 y 40 años. Afirman que no les gusta "molestar" a sus seguidores con estrategias tipo "etiqueta a x personas", plantear preguntas para que contesten, sorteos, etc. Por tanto, prefieren que la comunidad funcione de forma orgánica, sin hacer ningún tipo de llamada a la acción ni intervenir en ella, aunque sí que interpelan a su comunidad regularmente, buscando complicidades para compartir problemas y soluciones.

\section{CONCLUSIONES. ECO- INFLUENCERS: ENTRE EL ACTIVISMO Y EL MERCADO}

En el proceso de realización de esta investigación se han analizado diferentes tipos de perfiles que se dedican a la divulgación de contenidos sobre sostenibilidad: desde la promoción de compra de productos ecológicos, hasta perfiles de carácter indigenista, tiendas y perfiles comerciales, asociaciones, etc., todos ellos con conexiones y elementos en común, hecho que ha producido una cierta dificultad en su categorización claramente como "activistas". Esta mezcla de activismo digital que se vincula con la emergencia de un mercado de productos ecológicos sería, pues, una de las especificidades de la figura del eco-influencer.

También se ha observado una elevada presencia femenina en este sector y un tipo de perfil promovido por familias y parejas, como el caso de estudio propuesto, que se distancia de la idea de influencer individual y que podría tener un cierto recorrido en este contexto. Teniendo en cuenta el sesgo que haya podido producir el algoritmo a la hora de sugerir determinadas cuentas para entrar a formar parte de nuestra muestra, vemos que el conjunto analizado forma parte de lo que hemos denominado una "eco esfera", en el sentido de que las cuentas se relacionan y se siguen entre sí, y, en algunos casos, se han propuesto colaboraciones entre ellas.

A partir del análisis conjunto de cuentas y el estudio de caso se ha intentado conceptualizar la emergencia de este nuevo fenómeno detectado en el cruce entre la narrativa personal y el activismo medioambiental, que se articula a través de la idea de estilo de vida como una posibilidad de ejercer el activismo desde las pequeñas acciones diarias y modulando nuestra capacidad de consumo. 
En cuanto a las narrativas, se podría decir que buena parte de las cuentas estudiadas proponen un estilo de vida y estética verde como una forma de cambio social (Autio et al., 2009), y presentan una solución al cambio climático en términos positivos con el fin de seducir al máximo número de personas. Ahora bien, ¿podemos hablar de activismo? O ¿puede ser el activismo compatible con las dinámicas del mercado y de los influencers de Instagram?

De acuerdo con la observación de las cuentas y las entrevistas realizadas se puede afirmar que se trata de activismo, pero con unas características propias que encajan bien con la definición dada por Haenfler et al. (2012) para los lifestyle movements. Se trata de un activismo vinculado a la vida personal, que impulsa un estilo de vida concreto basado en la sustentabilidad, que a su vez se imbrica con un mercado emergente para proveer al movimiento de los productos que necesita para llevar a cabo su aspiración de una "buena vida", que contribuya a paliar el cambio climático.

En este sentido, es importante continuar observando la fusión entre las nociones de activismo e influencers, teniendo en cuenta la no banalización de los conceptos de estilo de vida en la capacidad de movilización y activación de cambios sociales. De alguna manera, el estilo de vida que articulan las narraciones personales actúa como movilizador para el cambio.

De hecho, no existe un consenso sobre la denominación de este fenómeno, ya que de manera más generalizada la idea de eco-influencer es muy nueva y todavía se asocia a celebrities más convencionales, como Leonardo DiCaprio o incluso Greta Thunberg. En este texto se propone ampliar el término eco-influencer a estos activistas medioambientales capaces de atraer a un gran número de seguidores y que centran su actividad en promover cambios en nuestro estilo de vida y nuestras prácticas domésticas, con una filosofía basada en "pequeños cambios" individuales para generar grandes cambios colectivos, que reta la concepción más clásica de movimiento social vinculado a una ideología política.

En cuanto al activismo visual, se puede afirmar que la mayor parte de las cuentas estudiadas tienen una imagen cuidada y una estética propia. En particular en el caso de @vivirsinplastico observamos que existe una apreciación por las imágenes realizadas con cierto esmero. Ellos piensan que una estética cuidada contribuye a la difusión de su lucha a favor del medio ambiente. Esta idea entra en conflicto con determinadas concepciones del activismo visual, como algo basado en la banalidad o la superficialidad de las imágenes y que restaría efectividad a la 'causa'. En este sentido, los ejemplos estudiados en esta investigación encajarían con la cultura de Instagram en sus formas de presentación de contenidos de un modo estético para articular una propuesta de vida. Este planteamiento estaría más en la línea de otros autores que apuntan a la capacidad transformadora de la estética (Calvera, 2007; Lipovetsky \& Serroy, 2015). Por tanto, esta combinación entre estética, activismo y vida cotidiana puede tener recorrido y provocar cambios sociales de un modo directo y sostenido. Más allá de los medios de comunicación convencionales y de los movimientos sociales basados en la acción colectiva en el espacio público, los eco-influencers proponen, a través de una estética cuidada, entender la acción política como una intervención práctica y bella sobre el mundo. Estaremos pendientes de su evolución. 


\section{REFERENCIAS}

Abidin, C., Brockington, D., Goodman, M. K., Mostafanezhad, M., \& Richey, L. A. (2020). The Tropes of Celebrity Environmentalism. Annual Review of Environment and Resources, (45), 1-15.

https://doi.org/10.1146/annurev-environ-012320-081703

Ardèvol, E., \& Gómez-Cruz, E. (2012). Digital Ethnography and Media Practices. The International Encyclopedia of Media Studies, 498-518. https://doi. org/10.1002/9781444361506.wbiems193

Ardèvol, E., \& Márquez, I. (2017). El youtuber como celebridad mediática: entre la autenticidad y el mercado. Rizoma, 5(2), 72-87.

http://dx.doi.org/10.17058/rzm.v5i2.11288

Ardèvol, E., Martorell, S., \& San Cornelio, G. (2021). El mito en las narrativas visuales del activismo medioambiental en Instagram. Comunicar, 68. https://doi.org/10.3916/C68-2021-05

Arlt, D., Hoppe, I., \& Wolling, J. (2011). Climate change and media usage: Effects on problem awareness and behavioural intentions. International Communication Gazette, 73(1-2), 45-53. https://doi. org/10.1177/1748048510386741

Autio, M., Heiskanen, E., \& Heinonen, V. (2009). Narratives of 'green' consumers - the antihero, the environmental hero and the anarchist. Journal of Consumer Behaviour: An International Research Review, 8(1), 40-53. https://doi.org/10.1002/cb.272

Black, I. R., \& Cherrier, H. (2010). Anti-consumption as part of living a sustainable lifestyle: Daily practices, contextual motivations and subjective values. Journal of Consumer Behaviour, 9(6), 437-453. https://onlinelibrary. wiley.com/doi/10.1002/cb.337

Calvera, A. (ed.). (2007). De lo bello de las cosas. Editorial Gustavo Gili.

Cuenca-Piqueras, C., González-Moreno, M. J., \& Checa-Olmos, J. C. (2021). ¿Empoderadas u objetivadas? Análisis de las ciberfeminidades en las influencers de moda. Investigaciones Feministas, 12(1), 19-30. https://dx.doi.org/10.5209/infe.68810

Demos, T. J. (2016). Between Rebel Creativity and Reification: For and Against Visual Activism. Journal of Visual Culture, 15(1), 85-102.

https://doi.org/10.1177/1470412915619459

Doerr N., \& Teune S. (2012). The Imagery of Power Facing the Power of Imagery: Toward a Visual Analysis of Social Movements, en: Fahlenbrach, K., Klimke, M., Scharloth, J. \& Wong, L. The Establishment Responds (43-55). Palgrave Macmillan. 
Featherstone, M. (1987). Lifestyle and Consumer Culture. Theory, Culture \& Society, 4(1), 55-70. https://doi.org/10.1177/026327687004001003

Filgueiras-Santos, T. (2019). As "eco" influenciadoras digitais e o desafio de engajar seguidores nas questões ambientais. en: Basílio de Simões, R. Marques, M. \& Figueira, J. Media, informação e literacia: rumos e perspectivas. Coimbra University Press.

Georgakopoulou, A. (2016). The SAGE Handbook of Social Media Research Methods. Sage.

Haenfler, R., Johnson, B., \& Jones, E. (2012). Lifestyle Movements: Exploring the Intersection of Lifestyle and Social Movements. Social Movement Studies, 11(1), 1-20. https://doi.org/10.1080/14742837.2012.640535

Hine, C. (ed.). (2005). Virtual Methods: Issues in Social Research on the Internet. Berg Publishers.

Holbert, R. L., Kwak, N., \& Shah, D. V. (2003). Environmental Concern, Patterns of Television Viewing, and Pro-Environmental Behaviors: Integrating Models of Media Consumption and Effects. Journal of Broadcasting \& Electronic Media, 47(2), 177-196. https://doi.org/10.1207/s15506878jobem4702_2

Holzer, B. (2006). Political Consumerism Between Individual Choice and Collective Action: Social Movements, Role Mobilization and Signalling. International Journal of Consumer Studies, 30(5), 405-415. https://doi. org/10.1111/j.1470-6431.2006.00538.x

Huang, H. (2016). Media use, environmental beliefs, self-efficacy, and pro-environmental behavior. Journal of Business Research, 69(6), 2206-2212. https://doi.org/10.1016/j.jbusres.2015.12.031

Leaver, T., Highfield, T., \& Abidin, C. (2020). Instagram: Visual Social Media Cultures. John Wiley \& Sons.

Leviston, Z., Price, J., \& Bishop, B. (2014). Imagining climate change: The role of implicit associations and affective psychological distancing in climate change responses. European Journal of Social Psychology, 44(5), 441-454. https://doi.org/10.1002/ejsp.2050

Lipovetsky, G., \& Serroy, J. (2015). La estetización del mundo. Vivir en la época del capitalismo artístico. Anagrama.

Marauri-Castillo, I., Rodríguez-González, M. M., Armentia-Vizuete, I., \& Marín-Murillo, F. (2021). Estrategia exitosa de información sobre alimentación dirigida a 'millennials': el caso de Carlos Ríos en Instagram. Revista Mediterránea de Comunicación, 12(1), 253-267. https://doi.org/10.14198/ MEDCOM000001

Markham, A. (2013). Remix Cultures, Remix Methods: Reframing Qualitative Inquiry for Social Media Contexts. en: Denzin, N. K., \& Giardina, M. D. 8th International Congress of Qualitative Inquiry (63-81). Routledge. 
Marwick, A. E. (2013). Status Update: Celebrity, Publicity, and Branding in the Social Media Age. Yale University Press.

Murphy, M. (2019). Zero Waste on Instagram Through the Lens of Precautionary Consumption. Gettysburg Social Sciences Review, 3(1), 3.

Olausson, U. (2011). "We're the Ones to Blame": Citizens' Representations of Climate Change and the Role of the Media. Environmental Communication, 5(3), 281-299. https://doi.org/10.1080/17524032.2011.585026

Östman, J. (2014). The Influence of Media Use on Environmental Engagement: A Political Socialization Approach. Environmental Communication, 8(1), 92-109._https://doi.org/10.1080/17524032.2013.846271

Pihkala, P. (2018). Eco-anxiety, tragedy, and hope: psychological and spiritual dimensions of climate change. Zygon®, 53(2), 545-569. https://doi. org/10.1111/zygo.12407

Pino-Romero, C., \& Castelló-Martínez, A. (2017). La estrategia publicitaria basada en influencers. El caso de SmartGirl by Samsung. En A. Castelló Martínez, C. \& Pino-Romero, C. (coord.). Publicidad y Convergencia Mediática. Nuevas estrategias de comunicación persuasiva (pp. 116-146). Egregius Ediciones.

Postill, J. (2018). The Rise of Nerd Politics. Digital Activism and Political Change. Pluto Press.

Segarra-Saavedra, J., \& Hidalgo-Marí, T. (2018). Influencers, moda femenina e Instagram: el poder de prescripción en la era 2.0. Revista Mediterránea de Comunicación, 9(1), 313-325. https://doi.org/10.14198/MEDCOM2018.9.1.17

Schlosberg, D., \& Coles, R. (2016). The new environmentalism of everyday life: Sustainability, material flows and movements. Contemporary Political Theory, 15, 160-181. https://doi.org/10.1057/cpt.2015.34

Senft, T. M. (2013). Microcelebrity and the Branded Self. A Companion to New Media Dynamics, 346-354. https://doi.org/10.1002/9781118321607. ch22

Shabir, H. (2020). The representation of sustainability on social media: an ecofeminist reading of Instagram. en: Master Thesis Series in Environmental Studies and Sustainability Science MESM02 20211. Lund University Centre for Sustainability Studies.

Strauss, A., \& Corbin, J. (1994). Grounded theory methodology. Handbook of qualitative research, 17(1), 273-285. https://doi.org/10.1093/acrefore/9780190228613.013.522

Treré, E. (2018). Hybrid Media Activism: Ecologies, Imaginaries, Algorithms. Routledge.

Vivir sin plástico. Entrevista. (24 noviembre 2020) 


\section{ANEXO 1: CUENTAS ANALIZADAS}

\begin{tabular}{|c|c|c|c|c|c|}
\hline @carlotabruna & $\begin{array}{c}\text { @gerardodel- } \\
\text { villar }\end{array}$ & $\begin{array}{c}\text { @trashisfortos- } \\
\text { sers }\end{array}$ & $\begin{array}{l}\text { @leonardodi- } \\
\text { caprio }\end{array}$ & @luisaneubauer & @gretathunberg \\
\hline @vivirsinplastico & $\begin{array}{l}\text { @sustaina- } \\
\text { ble_duo }\end{array}$ & @margreen_s & $\begin{array}{c}\text { @laurainwater- } \\
\text { land }\end{array}$ & $\begin{array}{l}\text { @greentipsca- } \\
\text { riuma }\end{array}$ & $\begin{array}{c}\text { @the_plastic_free_ } \\
\text { people }\end{array}$ \\
\hline @marianamatija & @petitapetjada & @kortajarenajon & $\begin{array}{l}\text { @Happy_Pla- } \\
\text { net_Lifestyle }\end{array}$ & @ecogodess & @nubiaehijos \\
\hline @goodkarmamart & @julicarvajal33 & @nancy_rysol & @ecoquotes & $\begin{array}{l}\text { @zerowastesto- } \\
\text { reecuador }\end{array}$ & @zerowastestore \\
\hline @verdealalma & $\begin{array}{c}\text { @publiclands- } \\
\text { hateyou }\end{array}$ & $\begin{array}{l}\text { @fridaysforfutu- } \\
\text { re.de }\end{array}$ & $\begin{array}{c}\text { @reducewaste- } \\
\text { now }\end{array}$ & $\begin{array}{l}\text { @about_envi- } \\
\text { ronment }\end{array}$ & @kristenanniebell \\
\hline @get.waste.ed & @futureearth & $\begin{array}{l}\text { @elcambiolo- } \\
\text { gico }\end{array}$ & $\begin{array}{l}\text { @planteaen- } \\
\text { verde }\end{array}$ & @ilovecyclo & @ecologistas \\
\hline @easyecotips_es & $\begin{array}{l}\text { @unpackeds- } \\
\text { hop }\end{array}$ & @ceroresiduo & @esturirafi & @usaryreusar & @sinplastico \\
\hline @ecoinventos & $\begin{array}{l}\text { @mindbody- } \\
\text { green }\end{array}$ & $\begin{array}{l}\text { @zerowaste- } \\
\text { home }\end{array}$ & $\begin{array}{c}\text { @chicksforcli- } \\
\text { mate }\end{array}$ & @zeroxplastic & @goingzerowaste \\
\hline @unep & $\begin{array}{c}\text { @the.eco. } \\
\text { warrior }\end{array}$ & @greenpeace & $\begin{array}{c}\text { @thezerowaste- } \\
\text { guide }\end{array}$ & $\begin{array}{c}\text { @wastefreepla- } \\
\text { net }\end{array}$ & @amenityofnature \\
\hline @noe_ona & $\begin{array}{l}\text { @honeycom_li- } \\
\text { ving }\end{array}$ & @mujer.semilla & $\begin{array}{c}\text { @packagefrees- } \\
\text { hop }\end{array}$ & $\begin{array}{c}\text { @planet_pre- } \\
\text { server }\end{array}$ & $\begin{array}{l}\text { @need.eco. } \\
\text { friendly }\end{array}$ \\
\hline
\end{tabular}

\section{ANEXO 2: ENTREVISTAS REALIZADAS (POR ORDEN CRONOLÓGICO):}

\begin{tabular}{|c|c|c|}
\hline 1 & @vivirsinplastico & $24 / 11 / 2020$ \\
\hline 2 & @laurainwaterland & $22 / 12 / 2020$ \\
\hline 3 & @public_lands_hateyou & $28 / 12 / 2020$ \\
\hline 4 & @reducewastenow & $04 / 01 / 2021$ \\
\hline 5 & @easyEcoTips & $15 / 01 / 2021$ \\
\hline 6 & @petita_petjada & $20 / 01 / 2021$ \\
\hline 7 & @marianamatija & $01 / 03 / 2021$ \\
\hline 8 & @usaryreusar & $07 / 04 / 2021$ \\
\hline 9 & @esturirafi & $13 / 04 / 2021$ \\
\hline 10 & @unpackedshop & $19 / 04 / 2021$ \\
\hline 11 & @planet_preserver & $20 / 04 / 2021$ \\
\hline 12 & @noe_ona & $28 / 04 / 2021$ \\
\hline 13 & @ilovecyclo & $11 / 05 / 2021$ \\
\hline
\end{tabular}

